\title{
Uncertainty Propagation Analysis for PWR Burnup Pin-Cell Benchmark by Monte Carlo Code McCARD
}

\author{
Ho Jin Park, ${ }^{1}$ Hyung Jin Shim, ${ }^{2}$ and Chang Hyo Kim ${ }^{2}$ \\ ${ }^{1}$ Reactor Core Design Division, Advanced Reactor Development Institute, Korea Atomic Energy Research Institute, \\ 989-111 Daedeok-Daero, Yuseong-gu, Daejeon 305-353, Republic of Korea \\ ${ }^{2}$ Department of Nuclear Engineering, Seoul National University, 1 Gwanak-ro, Gwanak-gu, Seoul 151-744, Republic of Korea
}

Correspondence should be addressed to Hyung Jin Shim, shimhj@snu.ac.kr

Received 31 July 2012; Accepted 9 October 2012

Academic Editor: Oscar Cabellos

Copyright ( 2012 Ho Jin Park et al. This is an open access article distributed under the Creative Commons Attribution License, which permits unrestricted use, distribution, and reproduction in any medium, provided the original work is properly cited.

\begin{abstract}
In the Monte Carlo (MC) burnup analyses, the uncertainty of a tally estimate at a burnup step may be induced from four sources: the statistical uncertainty caused by a finite number of simulations, the nuclear covariance data, uncertainties of number densities, and cross-correlations between the nuclear data and the number densities. In this paper, the uncertainties of $k_{\text {inf }}$, reaction rates, and number densities for a PWR pin-cell benchmark problem are quantified by an uncertainty propagation formulation in the MC burnup calculations. The required sensitivities of tallied parameters to the microscopic cross-sections and the number densities are estimated by the MC differential operator sampling method accompanied by the fission source perturbation. The uncertainty propagation analyses are conducted with two nuclear covariance data-ENDF/B-VII.1 and SCALE6.1/COVA libraries-and the numerical results are compared with each other.
\end{abstract}

\section{Introduction}

Monte Carlo (MC) burnup analysis codes [1-5] have been successfully applied for the neutronics design and analysis of advanced nuclear systems with increasing computing power. Since Takeda et al. [6] first proposed a formulation to evaluate the uncertainty propagation of number densities in the MC burnup analysis using the sensitivities of the burnup matrix to cross-sections and number densities, several studies [7-11] on the uncertainty propagation of MC burnup analysis followed with different uncertainty quantification formulations.

The uncertainty quantification of a nuclear parameter, such as $k_{\text {eff }}$, reaction rates, and number densities, in the MC burnup analysis is currently conducted by two different approaches: the sensitivity and uncertainty $(\mathrm{S} / \mathrm{U})$ analysis [12] and the direct stochastic sampling methods. In the $\mathrm{S} / \mathrm{U}$ analysis, the output uncertainty is quantified from its sensitivities to input parameters by the error propagation formulations. It provides explicit sensitivities but may suffer from low-order approximations. Park et al. [9] have established an uncertainty propagation formulation based on the $\mathrm{S} / \mathrm{U}$ analysis in the depletion calculations and demonstrated its usefulness in terms of an incineration analysis of a transuranic fuel assembly by using the Seoul National University MC code, McCARD [4].

The direct stochastic sampling methods can produce output distributions from a number of MC calculations each with different input data set sampled. This approach is easy to implement by running existing MC neutronics analysis codes with different input data sets but at the expense of high computational costs. This approach includes the XSUSA/SCALE [10] and TMC/SERPENT [11] methods. García-Herranz et al. [8] have developed an MC hybrid method combining $\mathrm{MC}$ spectrum and burnup calculations to reduce the computation time in the direct stochastic sampling approach.

In this paper, we perform the McCARD uncertainty propagation analysis for a PWR burnup pin-cell benchmark, one of the OECD benchmarks for uncertainty analysis modeling (UAM) for design, operation, and safety analysis of LWRs [13]. The uncertainty propagation of tallied parameters due to the statistical, microscopic cross-section, and number density uncertainties is calculated from their 
TABle 1: Comparison of $k$ uncertainties due to the covariance of ${ }^{235} \mathrm{U}$ and ${ }^{238} \mathrm{U}$ from ENDF/B-VII.1 and SCALE6.1/COVA.

\begin{tabular}{|c|c|c|c|}
\hline \multicolumn{2}{|c|}{ Covariance data } & $\begin{array}{c}\text { ENDF/B-VII.1 } \\
44 \mathrm{G} \text { Cov. }\end{array}$ & $\begin{array}{l}\text { SCALE6.1/ } \\
\text { COVA-44G }\end{array}$ \\
\hline \multirow{5}{*}{$\begin{array}{l}\text { RSD due to }{ }^{235} \mathrm{U} \\
(\%)\end{array}$} & $v, v$ & 0.604 & 0.264 \\
\hline & $(n, \gamma),(n, \gamma)$ & 0.216 & 0.211 \\
\hline & $(n, \gamma),(n$, fis $)$ & 0.075 & 0.076 \\
\hline & $(n, \mathrm{fis}),(n, \mathrm{fis})$ & 0.081 & 0.075 \\
\hline & $\left(n, n^{\prime}\right),\left(n, n^{\prime}\right)$ & 0.001 & 0.002 \\
\hline \multirow{4}{*}{$\begin{array}{l}\text { RSD due to }{ }^{238} \mathrm{U} \\
(\%)\end{array}$} & $v, v$ & 0.071 & 0.070 \\
\hline & $(n, \gamma),(n, \gamma)$ & 0.294 & 0.263 \\
\hline & $(n$, fis $),(n$, fis $)$ & 0.016 & 0.015 \\
\hline & $\left(n, n^{\prime}\right),\left(n, n^{\prime}\right)$ & 0.104 & 0.105 \\
\hline \multicolumn{2}{|c|}{ Total } & 0.729 & 0.463 \\
\hline
\end{tabular}

TABLE 2: $k_{\text {inf }}$ 's and their uncertainties versus pin burnup with ENDF/B-VII.1 and SCALE6.1/COVA covariance data.

\begin{tabular}{lccc}
\hline \multirow{2}{*}{ Burnup (MWd/kgU) } & \multirow{2}{*}{$k_{\text {inf }}$} & \multicolumn{2}{c}{ RSD (\%) } \\
& & ENDF/B-VII.1 & SCALE6.1/ \\
C4G Cov. & COVA-44G \\
\hline 0.00 & 1.41701 & 0.731 & 0.469 \\
0.10 & 1.39073 & 0.729 & 0.475 \\
0.20 & 1.38327 & 0.726 & 0.465 \\
0.50 & 1.36993 & 0.718 & 0.462 \\
1.00 & 1.35687 & 0.714 & 0.455 \\
2.00 & 1.34292 & 0.697 & 0.455 \\
4.00 & 1.31499 & 0.666 & 0.446 \\
6.00 & 1.28805 & 0.637 & 0.444 \\
8.00 & 1.26320 & 0.608 & 0.448 \\
10.00 & 1.23924 & 0.588 & 0.452 \\
12.00 & 1.21683 & 0.569 & 0.464 \\
14.00 & 1.19584 & 0.557 & 0.465 \\
16.00 & 1.17646 & 0.532 & 0.478 \\
18.00 & 1.15745 & 0.517 & 0.488 \\
20.00 & 1.13972 & 0.499 & 0.492 \\
30.00 & 1.05605 & 0.449 & 0.530 \\
40.00 & 0.98051 & 0.397 & 0.579 \\
50.00 & 0.91289 & 0.403 & 0.633 \\
60.00 & 0.85671 & 0.411 & 0.682 \\
\hline & & &
\end{tabular}

sensitivities estimated by the MC perturbation techniques $[14,15]$ in the continuous-energy $\mathrm{MC}$ calculations. The numerical results with ENDF/B-VII.1 covariance data are compared with those from the SCALE6.1/COVA covariance libraries.

\section{McCARD Uncertainty Propagation Methodology}

The MC depletion calculations consist of the successive MC transport analyses with updating the material compositions. Microscopic reaction rates are estimated at every beginning of a burnup step by the MC transport calculations. They are then used to solve the depletion equation to update isotopic number densities at the end of the burnup step. Thus, the uncertainties of the MC estimates on reaction rates due to the statistical and nuclear data and number density uncertainties cause those of the updated number densities. With the progress of the stepwise MC burnup calculations, the $\mathrm{MC}$ reaction rate uncertainties of a burnup step propagate to the number density uncertainties of the burnup step and to those of the following burnup steps. Figure 1 shows the uncertainty propagation mechanism in the MC burnup analysis. In the figure, $N, x, r$, and $Q$ denote the number density, microscopic cross-section, microscopic reaction rate, and tally, respectively. $n, m, i, \alpha$, and $g$ are the indices of burnup step, region, nuclide, reaction type, and neutron energy, respectively. From the figure, one can see that the $S / U$ analyses need be performed to quantify the uncertainty of $Q$ in the $\mathrm{MC}$ transport calculations and the number density uncertainties in the depletion calculations.

In the McCARD uncertainty propagation formulation [9], the variance of $Q, \sigma^{2}[Q]$, is estimated by

$$
\begin{gathered}
\sigma^{2}[Q]=\sigma_{\mathrm{S}}^{2}[Q]+\sigma_{\mathrm{NN}}^{2}[Q]+\sigma_{\mathrm{XX}}^{2}[Q]+2 \sigma_{\mathrm{NX}}^{2}[Q], \\
\sigma_{\mathrm{NN}}^{2}[Q]=\sum_{m, i m^{\prime}, i^{\prime}} \operatorname{cov}\left[N_{m, i}^{n}, N_{m^{\prime}, i^{\prime}}^{n}\right]\left(\frac{\partial Q}{\partial N_{m, i}^{n}}\right)\left(\frac{\partial Q}{\partial N_{m^{\prime}, i^{\prime}}^{n}}\right), \\
\sigma_{\mathrm{XX}}^{2}[Q]=\sum_{i, \alpha, g g^{\prime}, \alpha^{\prime}, g^{\prime}} \operatorname{cov}\left[x_{\alpha, g^{\prime}}^{i} x_{\alpha^{\prime}, g^{\prime}}^{i^{\prime}}\right]\left(\frac{\partial Q}{\partial x_{\alpha, g}^{i}}\right)\left(\frac{\partial Q}{\partial x_{\alpha^{\prime}, g^{\prime}}^{i^{\prime}}}\right), \\
\sigma_{\mathrm{NX}}^{2}[Q]=\sum_{m, i i^{\prime}, \alpha^{\prime}, g^{\prime}} \operatorname{cov}\left[N_{m, i}^{n}, x_{\alpha^{\prime}, g^{\prime}}^{i^{\prime}}\right]\left(\frac{\partial Q}{\partial N_{m, i}^{n}}\right)\left(\frac{\partial Q}{\partial x_{\alpha^{\prime}, g^{\prime}}^{i^{\prime}}}\right) .
\end{gathered}
$$

$\sigma_{\mathrm{S}}^{2}$ denotes the statistical variance. It can be estimated by the sample variance or real variance estimation methods [16$18]$.

In the McCARD uncertainty propagation analysis, the partial derivatives in (2) are approximated as

$$
\frac{\partial Q}{\partial X} \cong \frac{Q(\bar{X}+\sigma[X])-Q(\bar{X})}{\sigma[X]}=\frac{\delta Q(X)}{\sigma[X]}
$$

where $X$ denotes $N$ or $x$. In the McCARD procedure, $\delta Q(X)$ in (3) are estimated by the differential operator sampling method [14] accompanied by the fission source perturbation [15]. 
TABLE 3: RSDs (\%) of one-group reaction rates with ENDF/B-VII.1 and SCALE6.1/COVA covariance data.

\begin{tabular}{|c|c|c|c|c|c|}
\hline Cov. data & Burnup (MWd/kgU) & ${ }^{235} \mathrm{U}(n, \gamma)$ & ${ }^{235} \mathrm{U}(n, \mathrm{fis})$ & ${ }^{238} \mathrm{U}(n, \gamma)$ & ${ }^{238} \mathrm{U}$ ( $\left.n, \mathrm{fis}\right)$ \\
\hline \multirow{7}{*}{ ENDF/B-VII.1 } & 0 & 1.35 & 0.53 & 0.94 & 3.97 \\
\hline & 10 & 1.45 & 0.69 & 0.87 & 3.97 \\
\hline & 20 & 1.55 & 0.88 & 0.83 & 3.85 \\
\hline & 30 & 1.62 & 1.06 & 0.79 & 3.88 \\
\hline & 40 & 1.73 & 1.28 & 0.76 & 3.79 \\
\hline & 50 & 1.79 & 1.43 & 0.67 & 3.80 \\
\hline & 60 & 1.88 & 1.60 & 0.70 & 3.71 \\
\hline \multirow{7}{*}{ SCALE 6.1/COVA-44G } & 0 & 1.38 & 0.51 & 0.82 & 3.77 \\
\hline & 10 & 1.46 & 0.61 & 0.81 & 3.89 \\
\hline & 20 & 1.55 & 0.79 & 0.75 & 3.85 \\
\hline & 30 & 1.58 & 0.90 & 0.73 & 3.77 \\
\hline & 40 & 1.63 & 1.04 & 0.68 & 3.83 \\
\hline & 50 & 1.69 & 1.18 & 0.64 & 3.81 \\
\hline & 60 & 1.75 & 1.29 & 0.66 & 3.79 \\
\hline
\end{tabular}

TABLE 4: RSDs (\%) of number densities with ENDF/B-VII.1 and SCALE6.1/COVA covariance data.

\begin{tabular}{|c|c|c|c|c|c|c|}
\hline Cov. data & Bunrup or time & ${ }^{235} \mathrm{U}$ & ${ }^{239} \mathrm{Pu}$ & ${ }^{240} \mathrm{Pu}$ & ${ }^{241} \mathrm{Pu}$ & ${ }^{242} \mathrm{Pu}$ \\
\hline \multirow{7}{*}{ ENDF/B-VII.1 } & $0 \mathrm{MWd} / \mathrm{kgU}$ & 0.00 & 0.00 & 0.00 & 0.00 & 0.00 \\
\hline & $10 \mathrm{MWd} / \mathrm{kgU}$ & 0.14 & 0.99 & 1.37 & 1.38 & 2.72 \\
\hline & $30 \mathrm{MWd} / \mathrm{kgU}$ & 0.58 & 1.47 & 1.78 & 1.31 & 2.47 \\
\hline & $50 \mathrm{MWd} / \mathrm{kgU}$ & 1.33 & 1.95 & 2.22 & 1.77 & 2.51 \\
\hline & Shutdown & 1.95 & 2.16 & 2.47 & 2.06 & 2.60 \\
\hline & 1 year cooling & 1.95 & 2.13 & 2.47 & 2.16 & 2.60 \\
\hline & 100 years cooling & 1.95 & 2.13 & 2.34 & 2.06 & 2.60 \\
\hline \multirow{7}{*}{ SCALE 6.1/COVA-44G } & $0 \mathrm{MWd} / \mathrm{kgU}$ & 0.00 & 0.00 & 0.00 & 0.00 & 0.00 \\
\hline & $10 \mathrm{MWd} / \mathrm{kgU}$ & 0.09 & 0.80 & 1.17 & 1.16 & 1.57 \\
\hline & $30 \mathrm{MWd} / \mathrm{kgU}$ & 0.43 & 1.11 & 1.46 & 0.97 & 0.42 \\
\hline & $50 \mathrm{MWd} / \mathrm{kgU}$ & 1.04 & 1.43 & 1.80 & 1.25 & 0.17 \\
\hline & Shutdown & 1.53 & 1.58 & 2.00 & 1.47 & 0.23 \\
\hline & 1 year cooling & 1.53 & 1.56 & 1.99 & 1.54 & 0.23 \\
\hline & 100 years cooling & 1.52 & 1.56 & 1.90 & 1.47 & 0.23 \\
\hline
\end{tabular}

In exactly the same way as above for the variance of $Q$, the variance of the number density in the depletion calculations can be written by

$$
\begin{gathered}
\sigma^{2}\left[N_{m, i}^{n+1}\right]=\sigma_{\mathrm{NN}}^{2}\left[N_{m, i}^{n+1}\right]+\sigma_{\mathrm{RR}}^{2}\left[N_{m, i}^{n+1}\right]+2 \sigma_{\mathrm{NR}}^{2}\left[N_{m, i}^{n+1}\right], \quad(4) \\
\sigma_{\mathrm{NN}}^{2}\left[N_{m, i}^{n+1}\right]=\sum_{i^{\prime}} \sum_{i^{\prime \prime}} \operatorname{cov}\left[N_{m, i^{\prime}}^{n}, N_{m, i^{\prime \prime}}^{n}\right]\left(\frac{\partial N_{m, i}^{n+1}}{\partial N_{m, i^{\prime}}^{n}}\right)\left(\frac{\partial N_{m, i}^{n+1}}{\partial N_{m, i^{\prime \prime}}^{n}}\right), \\
\sigma_{\mathrm{RR}}^{2}\left[N_{m, i}^{n+1}\right]=\sum_{j, \alpha} \sum_{j^{\prime}, \alpha^{\prime}} \operatorname{cov}\left[r_{m, j, \alpha}^{n}, r_{m, j^{\prime}, \alpha^{\prime}}^{n}\right]\left(\frac{\partial N_{m, i}^{n+1}}{\partial r_{m, j, \alpha}^{n}}\right)\left(\frac{\partial N_{m, i}^{n+1}}{\partial r_{m, j^{\prime}, \alpha^{\prime}}^{n}}\right), \\
\sigma_{\mathrm{NR}}^{2}\left[N_{m, i}^{n+1}\right]=\sum_{i^{\prime}} \sum_{j, \alpha} \operatorname{cov}\left[N_{m, i^{\prime}}^{n}, r_{m, j, \alpha}^{n}\right]\left(\frac{\partial N_{m, i}^{n+1}}{\partial N_{m, i^{\prime}}^{n}}\right)\left(\frac{\partial N_{m, i}^{n+1}}{\partial r_{m, j, \alpha}^{n}}\right) .
\end{gathered}
$$

In McCARD, the partial derivatives in (5) are approximated in the same way as (3) and obtained by the direct subtractions. The detailed algorithms are described in [9].

\section{UAM PWR Pin-Cell Burnup Benchmark}

The PWR burnup pin-cell benchmark problem in Phase I of the OECD LWR UAM benchmarks [13] is designed to address the uncertainties in the depletion calculation due to the basic nuclear data as well as the impact of processing of nuclear and covariance data. The benchmark represents the burnup uncertainty propagation analysis for a typical fuel rod from the TMI-1 PWR, $15 \times 15$ assembly with $4.85 \mathrm{w} / \mathrm{o}$ enrichment. Its final burnup is $61.28 \mathrm{GWd} / \mathrm{MTU}$ with the specific power of $33.58 \mathrm{~kW} / \mathrm{kgU}$.

The McCARD analyses are conducted with the continuous-energy cross-section libraries processed by NJOY [19] from the ENDF/B-VII.1 neutron libraries. The crosssection covariance data are taken from the ENDF/B-VII.1 and SCALE6.1/COVA-44G. The 44-group covariance data from the ENDF/B-VII.1 covariance libraries are generated by the ERRORR module in the NJOY code.

For the fresh burnup state of the TMI-1 pin-cell problem, the $k$ uncertainty due to the cross-section covariance data 


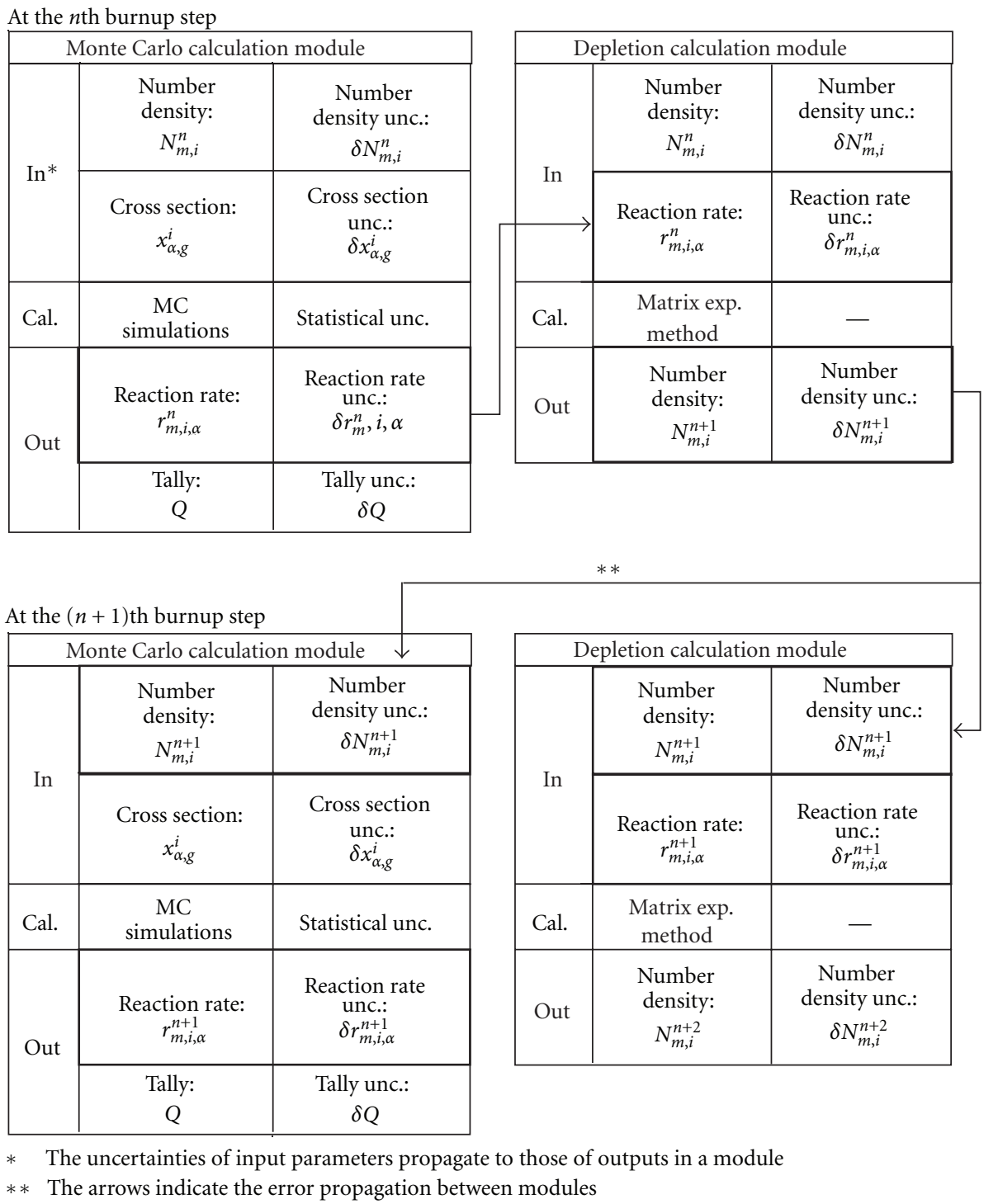

FIGURE 1: Uncertainty propagation in the MC burnup analysis.

is investigated by using McCARD. The $k$ uncertainty can be estimated by (1) ignoring $\sigma_{\mathrm{S}}^{2}, \sigma_{\mathrm{NN}}^{2}$, and $\sigma_{\mathrm{NX}}^{2}$. The McCARD eigenvalue calculations are performed on 1000 active cycles with 10,000 histories per cycle. In the MC perturbation calculations, the perturbed fission source distribution is assumed to converge after 10 cycles.

Table 1 shows the contributions of ${ }^{235} \mathrm{U}$ and ${ }^{238} \mathrm{U}$ crosssection uncertainties to the relative standard deviation (RSD) of $k_{\text {inf }}, \sigma_{X X}\left[k_{\text {inf }}\right]$, by reaction type and the covariance data. From Table 1, it is noted that the $k$ uncertainty from the ENDF/B-VII. 1 covariance data is $57 \%$ bigger than that from the SCALE6 covariance data and that contribution of the $v$ uncertainties of ${ }^{235} \mathrm{U}$ is a dominating factor to the $k$ uncertainty.

The MC burnup uncertainty propagation analyses are conducted by using the covariance data of 10 isotopes- ${ }^{235} \mathrm{U}$, ${ }^{238} \mathrm{U},{ }^{239} \mathrm{Pu},{ }^{240} \mathrm{Pu},{ }^{241} \mathrm{Pu},{ }^{242} \mathrm{Pu},{ }^{241} \mathrm{Am},{ }^{242 \mathrm{~m}} \mathrm{Am},{ }^{243} \mathrm{Am}$, and
${ }^{244} \mathrm{Cm}$. The McCARD eigenvalue calculations are performed on 100 active cycles with 10,000 histories per cycle. Table 2 shows the RSD of $k_{\text {inf }}$ as a function of the burnup steps for the two cases using the ENDF/B-VII.1 and SCALE6.1/COVA$44 \mathrm{G}$ covariance data. From the figures, one can observe that the $k$ uncertainties from the ENDF/B-VII.1 covariance data are decreasing, while those from SCALE6.1/COVA$44 \mathrm{G}$ are increasing, with the advancing burnup steps from $8 \mathrm{MWd} / \mathrm{kgU}$. Figures 2 and 3 show the contributions of $\sigma_{\mathrm{S}}$, $\sigma_{\mathrm{NN}}$, and $\sigma_{\mathrm{XX}}$ to the $k$ uncertainties from the ENDF/B-VII.1 and SCALE6.1/COVA-44G covariance data, respectively.

Table 3 shows the RSD of one group reaction rates versus pin burnup for the cases using the ENDF/B-VII.1 and SCALE6.1/COVA-44G covariance data. From the table, we can observe that there are no great differences between the reaction rate uncertainties estimated from the ENDF/B-VII.1 and SCALE6.1/COVA-44G covariance data. Table 4 shows 


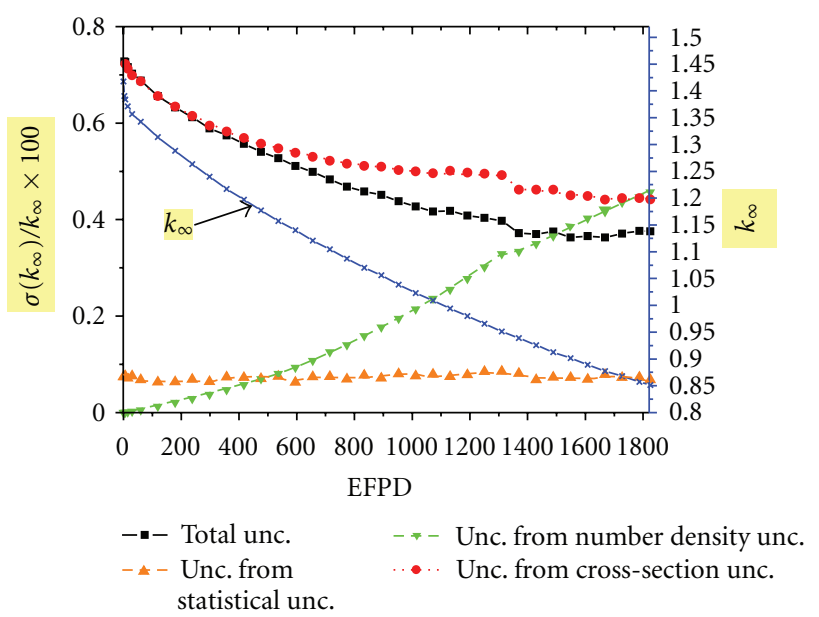

FIGURE 2: $k_{\text {inf }}$ and $\sigma\left[k_{\text {inf }}\right]$ versus pin burnup with ENDF/B-VII.1 covariance data.

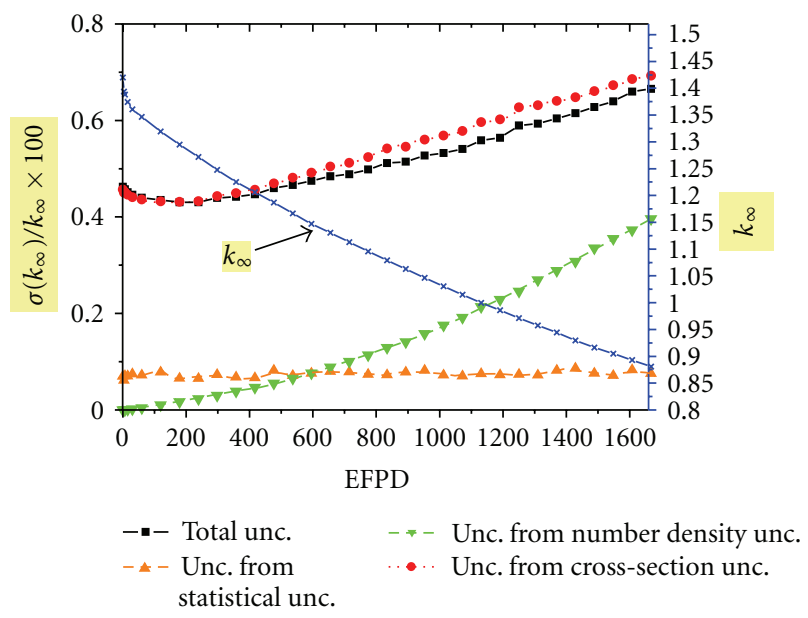

FIGURE 3: $k_{\text {inf }}$ and $\sigma\left[k_{\text {inf }}\right]$ versus pin burnup with SCALE6.1/COVA$43 \mathrm{G}$ covariance data.

RSDs of number densities estimated from the two covariance data as a function of, and the cooling time after, irradiation period.

\section{Conclusion}

The McCARD uncertainty propagation analyses with different covariance data files have been performed for the TMI-1 burnup pin-cell problem in Phase I of the OECD LWR UAM benchmarks. The numerical results show that the uncertainty behavior over burnup strongly depends on the nuclear covariance data.

\section{Acknowledgment}

This work was performed through the contract with Korea Institute of Nuclear Safety as part of its research project "Development of Licensing Technologies for Very High Temperature Reactor" which is funded by Ministry of Education and Science of Korea.

\section{References}

[1] D. L. Poston and H. R. Trellue, "User's manual, version 2.0 for MONTEBURNS version 1.0," LA-UR-99-4999, Los Alamos National Laboratory, 1999.

[2] J. S. Hendricks, G. W. McKinney, L. S. Waters, T. L. Roberts, H. W. Egdorf, J. P. Finch et al., "MCNPX, Version 2.5.E," LAUR04-0569, Los Alamos National Laboratory, 2004.

[3] K. Okumura, T. Mori, M. Nakagawa, and K. Kaneko, "Validation of a continuous-energy Monte Carlo burn-up code MVP-BURN and its application to analysis of post irradiation experiment," Journal of Nuclear Science and Technology, vol. 37, no. 2, pp. 128-138, 2000.

[4] H. J. Shim, B. S. Han, J. S. Jung, H. J. Park, and C. H. Kim, "McCARD: monte carlo code for advanced reactor design and analysis," Nuclear Engineering and Technology, vol. 44, no. 2, pp. 161-176, 2012.

[5] J. Leppänen, "PSG2/serpent-a continuous-energy monte carlo reactor physics burnup calculation code," VTT Technical Research Centre of Finland, 2008, http://montecarlo.vtt.fi/.

[6] T. Takeda, N. Hirokawa, and T. Noda, "Estimation of error propagation in Monte-Carlo burnup calculations," Journal of Nuclear Science and Technology, vol. 36, no. 9, pp. 738-745, 1999.

[7] M. Tohjoh, T. Endo, M. Watanabe, and A. Yamamoto, "Effect of error propagation of nuclide number densities on Monte Carlo burn-up calculations," Annals of Nuclear Energy, vol. 33, no. 17-18, pp. 1424-1436, 2006.

[8] N. García-Herranz, O. Cabellos, J. Sanz, J. Juan, and J. C. Kuijper, "Propagation of statistical and nuclear data uncertainties in Monte Carlo burn-up calculations," Annals of Nuclear Energy, vol. 35, no. 4, pp. 714-730, 2008.

[9] H. J. Park, H. J. Shim, and C. H. Kim, "Uncertainty propagation in monte carlo depletion analysis," Nuclear Science and Engineering, vol. 167, no. 3, pp. 196-208, 2011.

[10] W. Zwermann, L. Gallner, M. Klein, B. Krzykacz-Hausmann, A. Pautz, and K. Velkov, "XSUSA solution for the PWR Pincell burnup benchmark," in Proceedings of the 6th Workshop on OECD Benchmark for Uncertainty Analysis in Best-Estimate Modeling for Design, Operation and Safety Analysis of LWRs (UAM-6), Karlsruhe, Germany, May 2012.

[11] D. Rochmann and C. M. Sciolla, "Total Monte Carlo applied to Phase I-1: Burn-up Calculation," in Proceedings of the 6th Workshop on OECD Benchmark for Uncertainty Analysis in Best-Estimate Modeling for Design, Operation and Safety Analysis of LWRs (UAM-6), Karlsruhe, Germany, May 2012.

[12] D. G. Cacuci, Sensitivity and Uncertainty Analysis, Volume I: Theory, Chapman \& Hall/CRC, 2003.

[13] K. Ivanov, M. Avramova, S. Kamerow et al., "Benchmark for uncertainty analysis in modeling (UAM) for design, operation and safety analysis of LWRs, volume I: specification and support data for the neutronics cases (Phase I)," NEA/NSC/DOC, Nuclear Energy Agency, 2012.

[14] H. Rief, "Generalized Monte Carlo perturbation algorithms for correlated sampling and a second-order Taylor series approach," Annals of Nuclear Energy, vol. 11, no. 9, pp. 455476, 1984 .

[15] Y. Nagaya and T. Mori, "Impact of perturbed fission source on the effective multiplication factor in Monte Carlo perturbation calculations," Journal of Nuclear Science and Technology, vol. 42, no. 5, pp. 428-441, 2005.

[16] E. M. Gelbard and R. Prael, "Computation of standard deviations in Eigenvalue calculations," Progress in Nuclear Energy, vol. 24, no. 1-3, pp. 237-241, 1990. 
[17] T. Ueki, T. Mori, and M. Nakagawa, "Error estimations and their biases in Monte Carlo eigenvalue calculations," Nuclear Science and Engineering, vol. 125, no. 1, pp. 1-11, 1997.

[18] H. J. Shim and C. H. Kim, "Real variance estimation using an intercycle fission source correlation for Monte Carlo eigenvalue calculations," Nuclear Science and Engineering, vol. 162, no. 1, pp. 98-108, 2009.

[19] R. E. MacFarlane and D. W. Muir, "NJOY99.0 code system for producing pointwise and multigroup neutron and photon cross sections from ENDF/B data," PSR-480/NJOY99.0, Los Alamos National Laboratory, 2000. 

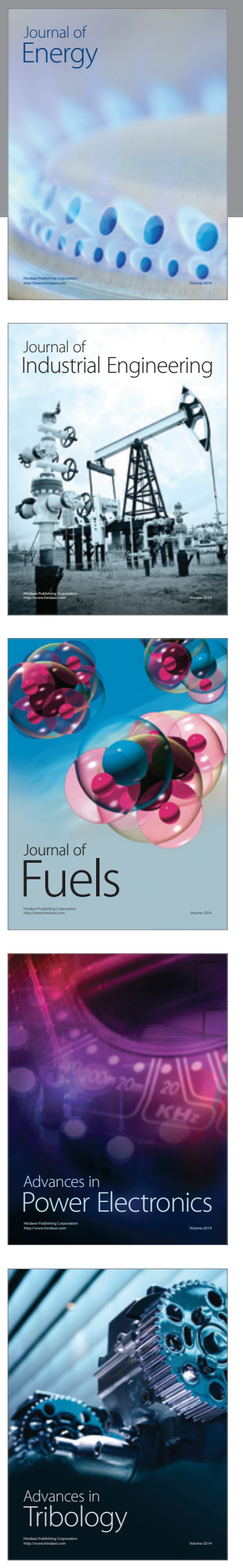
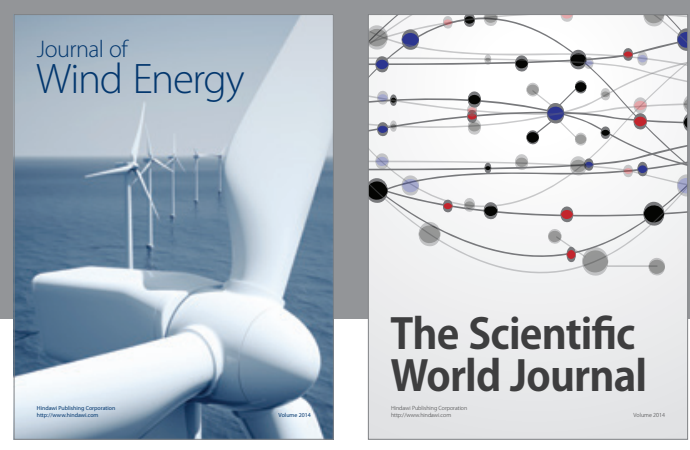

The Scientific World Journal

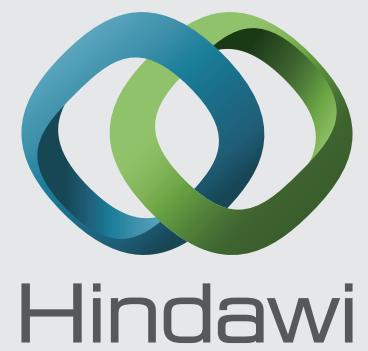

Submit your manuscripts at http://www.hindawi.com
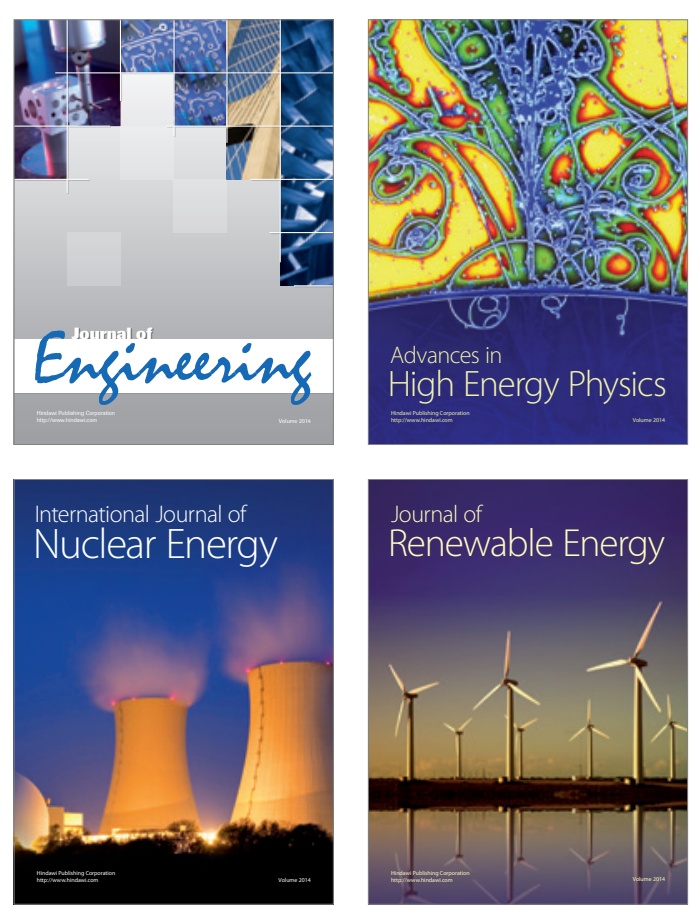

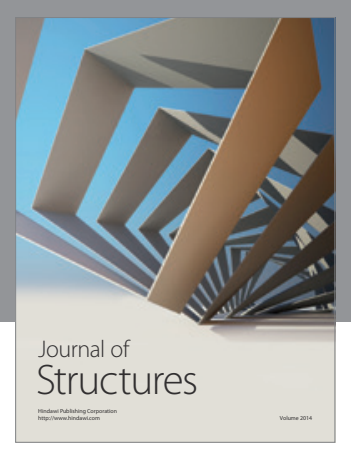

Rotating
Mechinery
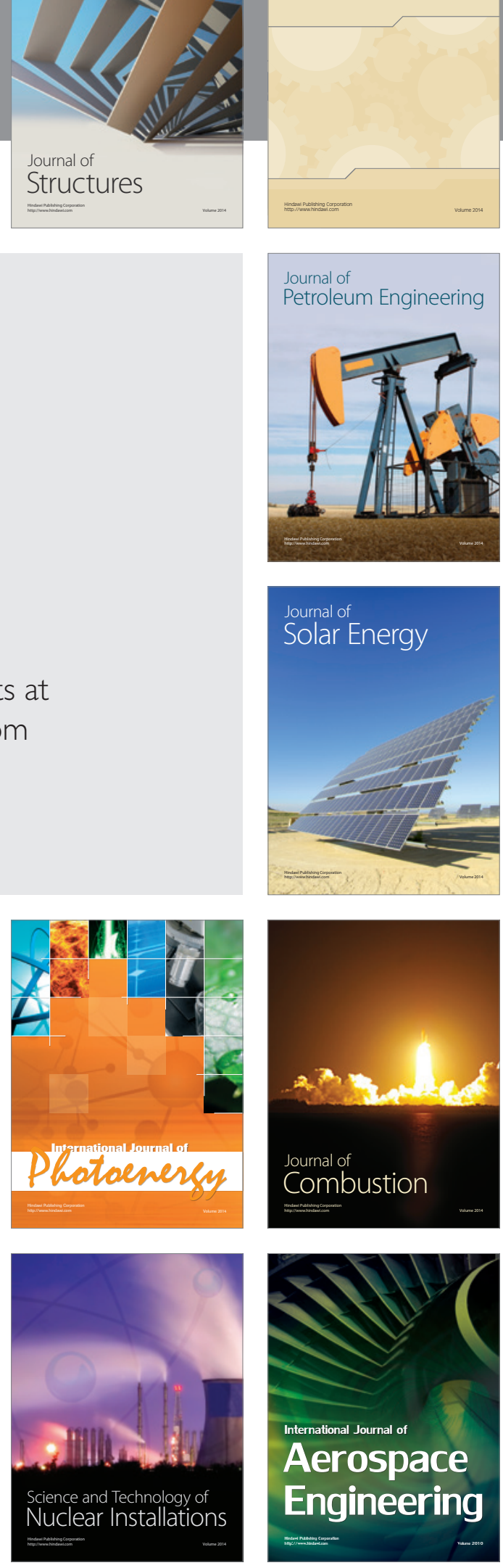